\title{
Estágio Supervisionado docente: Uma experiência vivenciada por licenciandos em Biologia em uma escola estadual de Teresina-PI
}

\author{
Supervised internship in Biology: An experience in a state school in Teresina-PI \\ Pasantía supervisada en biología: Una experiencia en una escuela pública en Teresina-PI
}

Recebido: 14/03/2021 | Revisado: 21/03/2021 | Aceito: 24/03/2021 | Publicado: 01/04/2021

Jailson do Nascimento Silva
ORCID: https://orcid.org/000-0002-6083-5320
Instituto Federal de Educação, Ciência e Tecnologia do Piauí, Brasil
E-mail: jailson.nascimento@ ifpi.edu.br
Marilha Vieira de Brito
ORCID: https://orcid.org/0000-0002-6658-2264
Universidade Federal do Piauí, Brasil
E-mail: marilhabio@ @otmail.com
Junielson Soares da Silva
ORCID: https://orcid.org/0000-0003-4872-2355
Secretaria de Educação do Piauí, Brasil
E-mail: junielsonbio10@gmail.com
Maria Raquel Veras de Carvalho
ORCID: https://orcid.org/0000-0001-8273-7804
Universidade Federal do Piauí, Brasil
E-mail: raquelveras@ @otmail.com.br
Gisele Holanda de Sá
ORCID: https://orcid.org/0000-0002-0687-9314
Universidade Federal do Piauí, Brasil
E-mail: giselehollanda2@gmail.com
Hernando Henrique Batista Leite
ORCID: https://orcid.org/0000-0002-3417-7141
Universidade Estadual do Maranhão, Brasil
E-mail: batista-leite@ hotmail.com
Verônica Brito da Silva
ORCID: https://orcid.org/0000-0001-7739-5061
Universidade Federal do Piauí, Brasil
E-mail: verabritosl@hotmail.com
Sérgio Emílio dos Santos Valente
ORCID: https://orcid.org/0000-0003-2953-7330
Universidade Federal do Piauí, Brasil
E-mail: svalente2@ yahoo.com.br

\begin{abstract}
Resumo
O Estágio Supervisionado docente é de grande importância para o licenciando, se configurando em uma oportunidade de ter contato com seu futuro ambiente de trabalho. A construção da identidade do professor não pode e nem deve ser considerada somente pelos conhecimentos teóricos adquiridos ao longo da sua formação, sendo o estágio docente o ápice do processo de formação inicial docente. Nesse sentido, a proposta deste trabalho é relatar, as experiências vivenciadas por licenciandos no estágio supervisionado docente em biologia, e suas contribuições para a formação do professor. Durante a convivência, pontos importantes para a formação de um bom profissional foram analisados, como a postura do professor e a capacidade de identificar as necessidades dos alunos e da turma como um todo. $\mathrm{O}$ estágio é um processo importante e indispensável para a formação docente. Ele possibilitou a assimilação da teoria e prática, pois através dele o licenciando vivenciou conflitos e dificuldades enfrentadas no dia a dia da sala de aula. Com o estágio, o futuro profissional pôde conhecer a dinâmica da escola, do processo de planejamento e realização das aulas, o comportamento dos alunos em sala de aula e o dia a dia da profissão. Assim, ficou evidente que esse momento se constitui de fundamental importância para o futuro professor.
\end{abstract}

Palavras-chave: Professor; Convivência; Estágio supervisionado; Teoria/Prática.

\begin{abstract}
The supervised teaching internship is of great importance for the licensee, becoming an opportunity to have contact with their future work environment. The construction of the teacher's identity cannot and should not be considered only due to the theoretical knowledge acquired throughout their training, with the teaching internship being the culmination of the initial teacher training process. In this sense, the purpose of this work is to report, the experiences
\end{abstract}


lived by undergraduate students in the supervised teaching stage in biology, and their contributions to teacher education. During the coexistence, important points for the formation of a good professional were analyzed, such as the teacher's posture and the ability to identify the needs of the students and the class as a whole. The internship is an important and indispensable process for teacher training. It enabled the assimilation of theory and practice, because through it the licensee experienced conflicts and difficulties faced in the classroom. With the internship, the future professional was able to learn about the dynamics of the school, the process of planning and conducting classes, the behavior of students in the classroom and the day-to-day life of the profession. Thus, it was evident that this moment is of fundamental importance for the future teacher.

Keywords: Teacher; Coexistence; Supervised internship; Theory / Practice.

\section{Resumen}

La pasantía docente supervisada es de gran importancia para el licenciatario, convirtiéndose en una oportunidad para tener contacto con su futuro entorno laboral. La construcción de la identidad del docente no puede ni debe ser considerada solo por los conocimientos teóricos adquiridos durante su formación, siendo la pasantía docente la culminación del proceso de formación inicial del docente. En este sentido, el propósito de este trabajo es informar, las experiencias vividas por los estudiantes de pregrado en la etapa de docencia supervisada en biología, y sus aportes a la formación docente. Durante la convivencia se analizaron puntos importantes para la formación de un buen profesional, como la postura del docente y la capacidad de identificar las necesidades de los alumnos y de la clase en su conjunto. La pasantía es un proceso importante e indispensable para la formación del profesorado. Permitió la asimilación de la teoría y la práctica, porque a través de ella el licenciatario experimentó los conflictos y las dificultades que enfrentaba en el aula. Con la pasantía, el futuro profesional pudo conocer la dinámica de la escuela, el proceso de planificación y realización de clases, el comportamiento de los estudiantes en el aula y el día a día de la profesión. Así, se hizo evidente que este momento es de fundamental importancia para el futuro docente.

Palabras clave: Maestro; Coexistencia; Pasantía supervisada; Teoría / Práctica.

\section{Introdução}

É fundamental que o licenciando, futuro professor, possa ter uma experiência de aproximação com a rotina da escola para entender a dinâmica da sala de aula, de forma que possa desenvolver habilidades essenciais à sua profissão. Com a criação de programas de incentivo à docência pelo Ministério da Educação - MEC, como o Programa Multidisciplinar de Residência Pedagógica (RP) e o Programa Institucional de Bolsas de Iniciação à Docência (Pibid), os licenciandos têm sido inseridos na realidade escolar cada vez mais cedo (Silva, Fernandes \& Soares, 2019; Santos et al., 2020). O convívio do licenciando é de suma importância para o desenvolvimento de uma prática pedagógica reflexiva baseada no contato com o contexto diário da realidade escolar, a qual deve ser produtiva e eficaz.

No entanto, sabe-se que por muito tempo e até hoje o estágio supervisionado obrigatório nos cursos de licenciatura se constitui como o momento em que o futuro professor terá a oportunidade de ter seu primeiro contato com o ambiente o ambiente escolar e de entender a dinâmica de uma sala de aula. Nesse momento, o futuro professor faz uma relação da sua vivência na escola, com a convivência junto aos estudantes e os problemas escolares com o conhecimento adquirido na formação universitária. Nesta etapa é muito comum acontecer uma ruptura entre teoria e prática, as quais estudada e o licenciando percebe que se trata de um ambiente dinâmico e com situações que nem sempre são previsíveis (Lima et. al. 2016).

De acordo com Nóvoa apud Mello (2012) “a maneira como o professor ensina está diretamente dependente daquilo que ele é como pessoa quando exerce o ensino". Essa afirmação reflete a proposta de elaboração deste estudo, que ver no estágio uma oportunidade de um contato com o contexto da realidade escolar. Toda carga teórica que o aluno-professor recebe, bem como sua observação e sua experiência constituem a formação do professor. E o tipo de educação e orientação a que ele é exposto influência na sua postura. É muito comum se observar a construção profissional do professor em formação como resultado da lapidação por outro profissional a qual ele se espelha. No entanto, ensinar é uma prática social, e como tal, é indispensável a convivência prática que propicia o contato com a realidade escolar e com a dinâmica do aprendizado dos alunos, porém esse contato deve ser acompanhado e orientado como qualquer outra atividade realizada por um profissional iniciante. Nesse sentido, para Silva e Emmel (2018, p. 183): 
"O estágio supervisionado é visto como uma via fundamental e essencial para a formação docente, pela pesquisa aproxima mais o licenciando da escola, desenvolvendo posturas e habilidades de pesquisador que visam compreender os fatores e aspectos importantes da realidade escolar."

Oliari et al. (2013) dizem que "a formação profissional é um processo que exige do professor um olhar crítico sobre suas representações pessoais, concepções e crenças sobre a educação, bem como sobre a instituição de ensino, as problemáticas sociais que se manifestam na escola, as formas de ensinar e aprender". Um professor de profissão não é somente alguém que aplica conhecimentos produzidos por outros, não é somente um agente determinado por mecanismos sociais: é um ator no sentido forte do termo, isto é, um sujeito que assume sua prática a partir dos significados que ele mesmo lhe dá, um sujeito que possui conhecimento e uma saber-fazer provenientes de sua própria atividade e a partir dos quais ele a estrutura e a orienta (Tardif, 2014).

Destarte é no exercício da prática que o futuro professor, ao participar de atividades que permeiam o cotidiano educacional, é contemplado com diferentes situações educativas que contribuirão para o seu processo de formação como docente no qual ele deverá, além de perceber a realidade, assumir uma atitude crítica mediante o contexto cultural, político, social e econômico em que a instituição educacional se insere (Lima et al., 2016).

Nesse cenário, o estágio supervisionado docente assume um papel fundamental, pois vai muito além do simples cumprimento de exigências acadêmicas. Ele é uma oportunidade de crescimento pessoal e em muitos casos, do primeiro contato com a prática profissional docente. Além de ser um importante instrumento de integração entre universidade, escola e comunidade (Filho, 2010). O estágio docente é de suma importância para preparar o futuro professor de Ciências e Biologia para a prática pedagógica, pois oferece momentos práticos que lhe permite reflexões sobre o papel do professor e sobre o "ser professor". Essa etapa que antecede sua atuação enquanto profissional docente, lhe proporciona o desenvolvimento de consciência de que ser professor é assumir uma postura pedagógica de investigação e não ser um repetidor de conhecimentos (Baptista, 2003).

Nesse sentido, observa-se que o futuro professor poderá pôr em prática a teoria assimilada nas diferentes disciplinas que compõem o currículo do seu curso formativo. Com isso, baseia-se no princípio metodológico de que o desenvolvimento profissional implica em utilizar conhecimentos adquiridos, quer na vida acadêmica ou pessoal. Sendo assim, o estágio supervisionado em licenciatura para o futuro professor, constitui-se num importante instrumento de conhecimento e de integração da realidade social, econômica e do trabalho em sua área profissional (Lima et al., 2016).

Os estudos e pesquisas que retratam sobre estágio supervisionado como componente curricular têm sido divulgados de forma mais sistemática no Encontro Nacional de Didática e Prática de Ensino - ENDIPE - e em apresentação de pesquisas e trocas de experiências ocorridas em eventos dessa natureza. Tais estudos não são dissociados da realidade histórico-social que os sustenta, mas acompanham a compreensão do estágio no processo histórico dessa disciplina no Brasil. É importante observar que a prática sempre esteve presente na formação do professor, e é, portanto, um instrumento fundamental para prepará-lo para seu ofício (Pimenta, 1994).

Segundo o Projeto Pedagógico do curso de licenciatura em Ciências Biológicas (PPC/Biologia/UFPI, 2019) presencial, da Universidade Federal do Piauí (UFPI), Campus Ministro Petrônio Portella, o estágio supervisionado obrigatório nos cursos de licenciatura é regulamentado pela Lei 11.788/2008. Devendo ser realizado em consonância com a Lei de Diretrizes e Bases da Educação - DBEN (9394/96). Possui diretrizes nacionais curriculares voltados à formação de professores da Educação Básica, e é considerado componente curricular indispensável para integralização da carga horária do curso (Resolução CNE/CP n ${ }^{\circ}$ 02/15 de 01/07/15). A realização do estágio no curso de Biologia da UFPI motivou a realização deste trabalho, que tem como objetivo relatar as experiências vivenciadas no estágio supervisionado docente, do curso de licenciatura em Biologia, bem como suas contribuições para a formação do professor. 


\section{Metodologia}

O estágio supervisionado constitui parte do currículo do curso de licenciatura em Biologia da Universidade Federal do Piauí (UFPI). Estes ocorrem nos períodos finais do curso, tem carga horária de 405 horas, divididos em três componentes curriculares denominados Estágio Supervisionado, com carga horária de 135 horas cada (PPC/Biologia/UFPI, 2019).

No presente trabalho usa-se como estratégica metodológica a pesquisa de natureza qualitativa. Uma vez que esta mostra-se a mais adequada por tratar-se de uma pesquisa baseada em observações, em ambiente natural com coleta direta de dados, e que leva em consideração a interpretação do pesquisador (Pereira et al., 2018).

O estágio de observação e regência aconteceu no período de 24 de março a 31 de maio de 2017, na Escola Estadual Cristino Castelo Branco, na zona norte de Teresina, Piauí, Brasil. Foi constituído por carga horária de 50 horas, sendo 25 no ensino fundamental e 25 horas no ensino médio, e foi dividido em três etapas: observação e análise do planejamento e estratégias didáticas dos professores; estrutura física da escola e realização de atividade de intervenção didático-pedagógica.

Durante a regência do estágio observou-se e anotou em diário de bordo os métodos de ensino utilizados pelos dois professores frente às necessidades da turma, ou seja, foi realizada uma observação inclinada a perceber se os professores utilizaram uma avaliação diagnóstica antes de escolher o método de ensino e o ponto onde começariam a ensinar. Foi observado as estratégias didáticas utilizadas para explanar os assuntos. Depois do conteúdo administrado foi observado também se os professores utilizavam métodos de avaliação quantitativos ou qualitativos ou ambos.

Partindo do princípio de que uma boa educação envolve também o conforto dos alunos durante as aulas, observou-se a estrutura física da escola como por exemplo a presença de assentos confortáveis, limpeza do ambiente e temperatura nas salas de aula, já que Teresina-PI apresenta altas médias de temperatura.

No final do estágio, foi realizado uma atividade de intervenção em sala com o conteúdo de botânica, objetivando proporcionar aos alunos um momento de aprendizado mais dinâmico, através da relação teoria e prática, que pudesse fazê-los se envolver com o processo de ensino e de aprendizagem. Com isso, foi desenvolvido uma prática em sala de aula onde os alunos trouxeram flores para identificação e descrição de seus órgãos reprodutivos (gineceu e androceu) e de suas estruturas não reprodutivas (cálice e corola). Após os desenhos das estruturas morfológicas das flores, foi explicado aos alunos a necessidade de se conhecer as estruturas para a identificação biológica de plantas. Além disso, explicou-se a importância da coloração das pétalas na atração de polinizadores, sendo associados a processos evolutivos que resultaram em adaptação dessas estruturas nas plantas para aumentar as chances de polinização e consequentemente de reprodução.

\section{Resultados e Discussão}

Foi observado que o professor de Biologia no ensino médio, iniciava as aulas sempre fazendo uma prévia avaliação para perceber o conhecimento dos alunos sobre o conteúdo a ser administrado. Com isso, ele norteava os caminhos a serem seguidos durante a aula. Podemos utilizar como exemplo, uma aula sobre fungos, onde foi perguntado aos alunos o que eles entendiam sobre fungos e algumas das respostas registradas são apresentadas a seguir:

Aluno A - "São massinhas 'as vezes brancas e 'as vezes escuras que dá na comida estragada".

Aluno B - "Algumas feridas que surgem na pele são causadas por fungos (micoses)".

Alunos C - "cogumelos que nascem em troncos também são fungos".

Diante dessas respostas o professor iniciava a aula expondo informações gerais a respeito do Reino Fungi e então chegava no grupo dos fungos citados pelos alunos. É notório que esse método torna as aulas muito mais interessantes, 
estimulando a curiosidade dos alunos, que ficam na expectativa de saber mais do que eles já têm uma certa ideia. Essa curiosidade desperta a atenção facilitando o entendimento do assunto abordado. Isso foi percebido com os resultados de uma atividade realizada em sala, e na avaliação quantitativa.

Por outro lado, foi verificado que a professora de Ciências no ensino fundamental não utilizou a avaliação diagnóstica no início das aulas, desenvolvendo isso ao longo das explicações, o que pareceu confundir os alunos. O conteúdo era explicado e ao longo da explicação sempre havia pausas para perguntar algo do que estava sendo abordado. Em uma aula sobre os estados físicos da matéria, a professora explicava o que era fusão e perguntava se era sublimação, quebrando o raciocínio da aula. Isso foi observado ao longo de várias aulas. Percebe-se que para um bom entendimento do aluno, uma aula deve ser sistemática e dinâmica, tomando os cuidados para que esta dinâmica não prejudique ou dificulte a aprendizagem dos discentes.

Essas observações corroboram com os posicionamentos de Madruga, Gallon \& Silva (2017), que relataram o fato dos estudantes possuírem conhecimentos obtidos por meio de observações e interações com o ambiente em que estão expostos e, também, por meio dos veículos de comunicação como TV e internet. Ainda sobre essa temática, os autores destacam que o professor deve se apropriar dessas ferramentas para garantir que os alunos cheguem em sala munidos de conhecimento e que a aula seja aproveitada para aprofundar o conhecimento. É preciso entender que é de fundamental importância que o professor compreenda que o diagnóstico inicial pode orientar sua prática e auxilia na reflexão sobre seu papel e sua formação. Entretanto, se os conhecimentos prévios dos seus alunos não forem adequadamente problematizados, pode ocorrer uma interferência no processo de aprendizagem do aluno, dificultando a apropriação do conhecimento sistematizado (Feijó \& Delizoicov, 2016).

Tanto o professor do ensino médio quanto o do ensino fundamental estavam preocupados em passar conteúdos e ver os resultados nas avaliações, dando ênfase na avaliação quantitativa em detrimento da qualitativa. A avaliação seguiu-se por meio de provas, exercícios em classe e extraclasse e, apenas no ensino médio, também por meio de seminários. Acredita-se que para o bom aproveitamento do potencial dos alunos é interessante que haja um balanceamento das duas formas de avaliações, tanto a qualitativa como a quantitativa, e principalmente, que a primeira se sobreponha à segunda, o que não foi observado pelos professores. Para Luckesi (1995), a avaliação reflete o acompanhamento do processo e dos resultados sucessivos que o educando vai obtendo em seu percurso de aprender, sendo a nota o registro do desempenho final desse percurso.

Ambos os professores procuraram associar teoria e prática. O professor do ensino médio costumava chegar com materiais para desenvolver atividades práticas em sala de aula. Em uma aula sobre artrópodes, o professor trouxe vários exemplares de insetos, piolho-de-cobra e aracnídeos para mostrar aos alunos o que foi visto na aula anterior. Tal fato mostrou a preocupação do professor em tornar o conteúdo mais interessante para seus alunos, bem como tornar prático o que foi visto na teoria. Isso tende a gerar nos estudantes motivação para aprender e se engajar com o processo de ensino e de aprendizagem.

A professora do ensino fundamental era muito dinâmica quanto às práticas. Em uma aula sobre modelos atômicos ela levou para sala um modelo feito de isopor e depois de uma breve explicação sobre o conteúdo, realizou-se uma atividade para os alunos identificarem e descreverem as partes que compõem o modelo atômico. Embora fosse apresentado os modelos já prontos, uma vez que seria pedagogicamente mais interessante propor aos alunos que desenvolvessem tais modelos. Mesmo assim, os alunos se mostraram interessados pela atividade e fizeram bastante perguntas, o que ajuda na fixação do conteúdo estudado. A associação entre teoria e prática vem se apresentando como um método transformador incluindo o aluno na realidade do assunto ensinado, além de oferecer um ambiente diferente para o estudante, despertando-lhe curiosidade e interesse pela disciplina (Pimentel, Oliveira \& Maciel). Por outro lado, aulas pautadas em métodos meramente expositivo limita-se apenas na abordagem de conceitos sem a utilização de materiais ou metodologias que facilitem a compreensão dos alunos levando a uma educação mecânica e de fácil esquecimento (Sousa et al., 2014; Goldschimidt et al., 2020). 
Krasilchik (2008) defende que em meio às modalidades didáticas existentes, as aulas práticas e projetos pedagógicos são os mais apropriados, pois, despertam e mantêm o interesse dos alunos; facilitam a compreensão de conceitos básicos; ampliam a capacidade de resolução de problemas; envolvem os estudantes em investigações científicas e desenvolvem habilidades. Segundo Alffonso (2019), as aulas práticas experimentais como as realizadas na observação desse estágio possuem impacto significativo no aprendizado do aluno, em Ciências e Biologia. Segundo o autor, os experimentos estimulam o interesse do aluno pelo conteúdo abordado por meio da associação da teoria com o fenômeno observado. Bomfim \& Dias (2013), destacam que mesmo nas escolas com laboratórios equipados para a realização das aulas práticas, estas ainda não ocorrem frequentemente, apesar da função pedagógica que estas exercem no desenvolvimento do aprendizado dos alunos. No entanto, durante a realização deste estágio, percebeu-se uma certa ruptura dessa barreira, onde os professores procuraram de algum modo desenvolver atividades práticas na própria sala de aula, tendo em vista que a escola não dispunha de laboratório.

Sobre a estrutura física, observou-se que a escola oferecia conforto no ambiente de ensino dispondo de salas de aula climatizadas e bem iluminadas; um laboratório de biologia com microscópios, vidrarias, reagentes e peças anatômicas. Fora do ambiente de aulas a escola era equipada com pátios, refeitórios, salas de professores climatizadas e uma área de lazer para intervalos. Nesse sentido, Monteiro e Silva (2015), após análise de uma escola no estágio supervisionado, concluíram que a sala de aula deve oferecer as mínimas condições de comodidade, tanto para o aluno quanto para o professor. Tendo em vista que é nesse espaço que são desenvolvidas atividades escolares importantes, como as relações do ensinar e do aprender.

Com relação à atividade de intervenção em campo, realizada no jardim da escola e nas proximidades dela, foram observadas as estruturas das flores e as diferentes colorações que existiam entre elas. Em sala, os alunos desenharam as estruturas morfológicas reprodutivas masculinas (androceu) e feminina (gineceu), bem como as estruturas não reprodutivas, conjunto de pétalas (corola) e de sépalas (cálice). Uma vez desenhado, os alunos identificaram cada estrutura tomando o livro didático como base. Percebeu-se durante a prática o entusiasmo dos alunos.

Em suma, pode-se destacar que o estágio supervisionado docente é um momento importante para o futuro professor, por oportunizar a vivência da rotina do ambiente escolar. Dessa forma, Borges et al. (2020) destacam que o "estágio supervisionado trará a verdade dos prazeres e desafios que o futuro professor enfrentará no seu dia-dia enquanto professor, aprendendo a lidar com as dificuldades diárias e conseguir atingir o seu maior objetivo, que é o da promoção do ensinoaprendizagem."

\section{Conclusão}

O estágio supervisionado docente em Biologia, foi um veículo de informação e experiência em sala de aula. Com ele pôde-se observar a importância de se conhecer a dinâmica de aprendizado da turma ao tomar decisões de qual metodologia a ser empregada para trabalhar um conteúdo utilizando estratégias didáticas que favoreçam o aprendizado do aluno, de acordo com o nível da turma e com os recursos disponibilizados pela escola.

Com o estágio docente, percebeu-se também o rumo que se deve seguir ao desenvolver um conteúdo com uma turma, tendo por base as necessidades da turma, levando em considerações fatores intrínsecos e extrínsecos aos alunos. Dessa forma, compreender melhor, aspectos relacionados a temáticas como importância de conhecimentos teórico prévios, aulas práticas e uma boa avaliação da aprendizagem é fundamental para a construção de um professor eficiente na transmissão e mediação do conhecimento, sendo portanto, o estágio supervisionado o momento em que o licenciando, futuro professor tem a oportunidade de experienciar todas essas vivencias e de agregar ao seu repertório docente conhecimentos teórico-prático que lhes serão fundamentais no dia a dia da sua profissão. 
Através dos resultados obtidos e das discussões levantadas com este presente estudo, torna-se possível o desenvolvimento de estudos futuros a respeito da temática com o intuito de demostrar e exemplificar melhor a importância do uso de aulas práticas e modalidades de avaliação da aprendizagem e também sugerir atividades nesse sentido.

\section{Referências}

Alffonso, C. M. (2019). Práticas inovadoras no ensino de ciências e biologia: diversidade na adversidade. Revista Formação e Prática Docente. 2, 69-85. http://www.revista.unifeso.edu.br/index.php/revistaformacaoepraticaunifeso/article/view/695/659.

Baptista, C. S. G. (2003). A importância da reflexão sobre a prática de ensino para a formação docente inicial em Ciências e Biológicas. Ensaio Pesquisa em Educação em Ciências. UFMG, 5(2), 4-12. https://doi.org/10.1590/1983-21172003050202.

Borges, I. M. S., Lima, C. A. O., Fernandes, A. C. G., Santos, P. L. A., Freire, J. G. T. B., Santos Junior, C. N., \& Santos, M. J. R. (2020). The importance of supervised internship and planning for geography teacher training: experience report. Research, Society and Development, 9(9), e541997566. https://doi.org/10.33448/rsd-v9i9.7566

Bomfim, G. S. \& Dias, V. B. (2012). Aulas de Ciências Naturais na educação infantil e ensino fundamental I, por alunas-professoras do curso de Pedagogia do PARFOR/UESC: relato de uma experiência. In: II Simpósio Baiano de Licenciaturas, 2012, Salvador. Anais do II Simpósio Baiano de Licenciaturas: política de formação de professores para a educação básica, Salvador.

Feijó, N. \& Delizoicov, N. C. Professores da educação básica: Conhecimento prévio e problematização. Revista Retratos da Escola, Brasília, 10(19), 597-610, jul./dez. 2016. https://doi.org/10.22420/rde.v10i19.643.

Filho, A. P. O. (2010). Estágio supervisionado e sua importância na formação docente. Revista partes. htttp://www.partes.com.br/educacao/estagiosupervisionado.asp.

Gonçalves, C. L. \& Pimenta, S. G. (1990). Revendo o ensino de 2 o Grau, propondo a formação do professor. Cortez.

Goldschimidt, A. I., Michel, D. C., Fontana, L. B., Rangel, C., Brizola da Silva, W., Novaes. L. A.; \& Tissot, C. (2020). Bicho de sete cabeças: uma proposta para o ensino da célula e da anatomia humana. REPPE: Revista do Programa de Pós-Graduação em Ensino. (4)2, 23-39. http://seer.uenp.edu.br/index.php/reppe/article/view/2000/914.

Krasilchik, M. (2008). Prática de Ensino de Biologia. (4a ed.), Editora da Universidade de São Paulo.

Lima, G. O., Santo, M. V. M. E., Filho, M. A. S. M. \& Silva, C. D. P. (2016) Teoria e Prática: Dificuldades Enfrentadas pelos Futuros Professores no Campo de Estágio Curricular Supervisionado no Curso de Pedagogia. Revista eletrônica Estácio, Recife, 1(3). https://reer.emnuvens.com.br/reer/article/view/85/33.

Luckesi, C. C. (1995). Avaliação da aprendizagem escolar: estudos e proposições. Cortez.

Madruga, Z. E. F, Gallon, M. S \& Silva, C. M. (2017). Percepções sobre os conhecimentos prévios em matemática nos anos iniciais e possíveis caminhos. Revista Exitus, Santarém/PA, 7(3), 146-171. https://doi.org/10.24065/2237-9460.2017v7n3ID352.

Mello, S. P. T \& Lindner, L. M. T. A contribuição dos estágios na formação docente: observações de alunos e professores. IX Anped Sul: Seminário de pesquisa em educação da região Sul, 2012.

Monteiro, J. S., Silva, D. P. (2015). A influência da estrutura escolar no processo de ensino-aprendizagem: uma análise baseada nas experiências do estágio supervisionado em Geografia. Geografia Ensino \& Pesquisa, 19, 19-28. https://periodicos.ufsm.br/geografia/article/viewFile/14315/pdf.

Morais, M. B. \& Paiva, M. H. (2009). Ciências-ensinar e aprender. Dimensão.

Oliari, F. A. S., Tenroller, R. M.; Roquette, R. F. \& Nez, E. (2016). Refletindo sobre a identidade e a formação do professor da educação superior. Revistas eletrônicas: Educação em Foco. https://portal.unisepe.com.br/unifia/wp-content/uploads/sites/10001/2018/06/1refletindo_sobre_identidade.

Pereira et al. (2018). Metodologia da pesquisa científica.

Piconez, S. C. (1991). A prática de ensino e o estágio supervisionado: a aproximação da realidade escolar e a prática da reflexão. IN: FAZENDA, Ivani Catarina Arantes [et all]; Piconez, S. A prática de ensino e o estágio supervisionado. Campinas-SP: Papirus.

Pimenta, S. G \& Anastasiou, L. G. C. (2002). Docência no ensino superior. Cortez.

Pimenta, S. G \& Lima, M. S. L. (2006). Estágio e docência: diferentes concepções. Revista Poíesis, Santa Catarina, 3(3), 5-24. https://doi.org/10.5216/rpp.v3i3e4.10542.

Pimentel, P. M. S., Oliveira, M. V. P., \& Maciel, E. M. (2017). Teoria e prática no âmbito do ensino médio: análise de casos no Piauí e Ceará para o ensino de biologia. REnCIMA. (8)3, 158-173. https://doi.org/10.26843/rencima.v8i3.1200 .

Pimenta, S. G. \& Lima, M. S. L(2004). Estágio e Docência. Cortez.

Pimenta, S. G. (2020). O estágio na formação de professores: unidade teoria e prática? Cortez.

PPC/Biologia/UFPI. (2019). Projeto Pedagógico do Curso de ciências biológicas - modalidade licenciatura (presencial). Universidade Federal do Piauí do Campus Ministro Petrônio Portella, Teresina-Piauí, 2019. 
Research, Society and Development, v. 10, n. 4, e10210413897, 2021

(CC BY 4.0) | ISSN 2525-3409 | DOI: http://dx.doi.org/10.33448/rsd-v10i4.13897

Sacristán, J. G. (1999). Poderes instáveis em educação. Porto Alegre, Artes Médicas. Schön, D. "Formar professores como profissionais reflexivos". In: Nóvoa, A. (Org.). Os professores e sua formação. Lisboa: Dom Quixote, 1992.

Santos, E. B., Martins, M., Silveira Ramos, M., Neto, H., \& Mazocco Paniz, C. (2020). A importância do Programa de Residência Pedagógica na formação de professores no Instituto Federal Farroupilha, Campus São Vicente do Sul. Revista Insignare Scientia - RIS, 3(1), 42-56. https://doi.org/10.36661/2595$4520.2020 \mathrm{v} 3 \mathrm{i} 1.11018$.

Silva, J. S. da, Fernandes, S. M. A., \& Soares, R. R. (2019). Importância do programa institucional de bolsas de iniciação à docência (PIBID) na formação dos acadêmicos do curso de ciências biológicas. Educação Em Perspectiva, 10, e019023. https://doi.org/10.22294/eduper/ppge/ufv.v10i0.7170.

Silva, S. A. \& Emmel, R. (2018). Reflexões da formação inicial de professores: o estágio supervisionado nos anos iniciais. Horizontes-Revista de Educação, 6(12), 181-192. https://ojs.ufgd.edu.br/index.php/horizontes/article/view/8302/5116.

Sousa, F. S., Silva, J. S., Paranhos, J. D. N. \& Dantas, S. M. M. M. (2014). As metodologias usadas por professores de ciências e biologia no processo de ensino/aprendizagem. Revista da SBEnBIO, 7, 2014-2022. https://docplayer.com.br/19573484-As-metodologias-usadas-por-professores-de-ciencias-ebiologia-no-processo-de-ensino-aprendizagem.html.

Tardif, M. (2014) Saberes docentes e formação profissional. (16a ed.), Vozes. 230-243. 